\title{
Perigo na tribo? \\ Notas sobre a percepção do jornalista enquanto categoria profissional a partir de um estudo com neófitos ${ }^{1}$
}

\author{
Ana Cristina Spannenberg ${ }^{2}$
}

Michelle Júnia Soares ${ }^{3}$

\begin{abstract}
Resumo: O artigo apresenta alguns dos resultados da pesquisa "Egressos do Jornalismo / UFU no mercado de trabalho" (SOARES, 2015), realizada em 2014 com os profissionais formados na primeira e segunda turmas do Curso de Comunicação Social: Habilitação em Jornalismo da Universidade Federal de Uberlândia. Os resultados a serem discutidos procuram demonstrar a fragilização da noção de categoria profissional entre jornalistas neófitos a partir de suas percepções sobre condições de trabalho, satisfação e dificuldades, registro profissional, obrigatoriedade do diploma, sindicalização e necessidade de autorregulamentação.
\end{abstract}

Palavras-chave: jornalista, categoria profissional, Jornalismo UFU, perfil, neófito.

Abstract: The article presents some results from the research "Egressos do Jornalismo / UFU no Mercado de trabalho" (SOARES, 2015), fulfilled in 2014 with professionals from first and second Social Commnunication classes: journalism degree of Uberlândia Federal University. The results to be discussed aim to demonstrate the fragility of professional category between neophytes journalists and their own perceptions about work conditions, satisfaction and difficulties, professional record, mandatory diploma, unionization and self-regulation necessities.

Keywords: journalist, professional category, journalism UFU, profile, neophyte.

\section{Introdução}

Alguns pesquisadores consideram os jornalistas como uma "tribo" por compartilharem uma "forma de ver" a realidade, formando uma "comunidade interpretativa" (TRAQUINA, 2005b), porém, as mudanças sofridas pelo mundo do trabalho, sobretudo nas três últimas décadas, estão cada vez mais fragilizando a noção de categoria profissional e,

\footnotetext{
${ }^{1}$ Uma versão inicial deste texto foi apresentada no $13^{\circ}$ Encontro Nacional de Pesquisadores de Jornalismo, promovido pela Sociedade Brasileira de Pesquisadores em Jornalismo (SBPJor), em novembro de 2015.

${ }^{2}$ Jornalista, professora do Curso de Comunicação Social com Habilitação em Jornalismo da Faculdade de Educação da Universidade Federal de Uberlândia, mestre em Comunicação e Cultura Contemporâneas (UFBA/2004) e doutora em Ciências Sociais (UFBA/2009) E-mail: anaspann@gmail.com.

${ }^{3}$ Jornalista formada pelo Curso de Comunicação Social com Habilitação em Jornalismo da Faculdade de Educação da Universidade Federal de Uberlândia E-mail: michellejunias@hotmail.com.
} 
consequentemente, a percepção desses profissionais enquanto grupo. Compreendemos que há diversos outros fatores que constituem a definição de jornalista (KUNCZIK, 2002; TRAQUINA, 2005a), mas pretendemos apresentar nesse artigo alguns dados que demonstram essa crescente fragilização, sobretudo pelos jornalistas neófitos. Estamos utilizando aqui o termo neófito para demarcar o jornalista recém-formado ou com até dois anos de inserção na profissão, que foi o público definido no estudo a ser apresentado.

A pesquisa "Egressos de Jornalismo/UFU no Mercado de Trabalho: Mapeamento Sobre Perfil e Inserção Profissional dos Jornalistas Formados pela Universidade Federal de Uberlândia" (SOARES, 2015) teve como objetivo identificar o perfil e a atuação dos formados pelo Curso de Jornalismo da UFU. Os resultados lançam luzes sobre uma série de aspectos envolvendo a profissão, porém neste artigo recortaremos aqueles que apontam para a percepção do profissional neófito enquanto categoria, tais como suas noções sobre condições de trabalho, satisfação e dificuldades, registro profissional, obrigatoriedade do diploma, sindicalização e necessidade de autorregulamentação.

É necessário ressaltar que o estudo mencionado traz duas importantes referências de temática similar: a pesquisa feita entre 2009 e 2012 intitulada " $O$ perfil dos jornalistas profissionais no Estado de São Paulo e o ponto de vista desse profissional sobre o seu trabalho" (FÍGARO; NONATO; GROHMANN, 2013), desenvolvida pelo Centro de Pesquisa em Comunicação e Trabalho da Escola de Comunicações e Artes da Universidade de São Paulo com apoio da Fundação de Amparo à Pesquisa no Estado de São Paulo (Fapesp), e a pesquisa realizada em 2012 e intitulada "Perfil do jornalista brasileiro - Características demográficas, políticas e do trabalho jornalístico" (PERFIL, 2012), realizada pelo Núcleo de Estudos sobre Transformações no Mundo do Trabalho da Universidade Federal de Santa Catarina, em parceria com o Programa de Pós-Graduação em Sociologia Política (PPGSP), em convênio com a Federação Nacional dos Jornalistas e com o apoio do Fórum Nacional de Professores de Jornalismo (FNPJ) e da Associação Brasileira de Pesquisadores do Jornalismo (SBPJor).

O presente texto está estruturado em três partes, além desta introdução. Em um primeiro momento discutiremos sucintamente o surgimento e consolidação do jornalismo enquanto profissão e, na sequência, abordaremos como esse processo se dá no cenário brasileiro. Depois serão apresentados o desenho da pesquisa, bem como alguns dos seus 
resultados, referentes aos itens acima mencionados. Para finalizar, discutiremos brevemente as nossas observações e os desafios que eles nos apontam.

\section{Jornalismo como categoria profissional}

A definição do que se considera como a profissão de jornalista é ainda amplamente discutida. Michael Kunczik (2002) afirma que os teóricos divergem nesse sentido, alguns consideram-na “[...] a profissão principal ou suplementar das pessoas que reúnem, detectam, avaliam ou difundem as notícias; ou que comentam os fatos do momento" (KOSZYK e PRUYS apud KUNCZIK, 2002, p. 16), outros, ainda oferecem uma visão mais ampla, abrangendo "[...] todos os trabalhadores em tempo integral e parcial dos meios de comunicação que participam da reunião, do processamento, da revisão e do comentário das notícias e/ou entretenimento" (KUNCZIK, 2002, p.16). Neste trabalho, adotaremos a solução proposta por Nelson Traquina que, após um exame cuidadoso do processo histórico de constituição da atividade jornalística, defende:

\footnotetext{
$\mathrm{Na}$ linha contínua das profissões, o jornalismo afasta-se do pólo identificado com um simples "trabalhador por conta de outrem" e aproxima-se do pólo identificado com as chamadas profissões liberais. Quem defende o contrário mantém a cabeça enterrada na areia, ignorante da corrente da história. (2005a, p.122-123)
}

Vale lançar um breve olhar sobre a história para compreender como se chega a tal construção. Nelson Traquina ${ }^{4}$ (2005a) descreve o processo de modernização da atividade jornalística, situado especialmente do século XIX, a partir de três vertentes: a expansão, a comercialização e a profissionalização. O processo de profissionalização, que é nosso foco de interesse neste trabalho, ocorre à medida que mais pessoas passam a dedicar-se integralmente à atividade jornalística e essa vai estabelecendo um conjunto de saberes específicos e regras

\footnotetext{
${ }^{4}$ No presente trabalho optamos por adotar as obras do pesquisador português Nelson Traquina (2005a, 2005b) como principal referência para discussão em torno da profissionalização jornalística por considerarmos que sua percepção de campo, seguindo a proposta de Pierre Bourdieu, que entende o jornalismo estruturado em dois polos, ideológico e econômico, como a mais adequada para observação do nosso objeto de estudo. Deve-se destacar, entretanto, que diversos outros pesquisadores debruçaram-se sobre o tema com importantes contribuições, sob perspectivas distintas, tais como a do espanhol Lorenzo Gomis (1991), a do italiano Mauro Wolf (1995), a do português Jorge Pedro Sousa (2000) e da estadunidense Barbie Zelizer (2004), além do pesquisador brasileiro Adelmo Genro Filho (1987), referência brasileira no estudo das Teorias do Jornalismo, e de obras anteriores do próprio Nelson Traquina (1993).
} 
profissionais que devem ser cumpridas. Conforme Michael Kunczik (2002), apenas no século XIX pode-se encontrar um movimento nesse sentido.

Traquina considera que a recém-implantada "democracia moderna" é que "[...] fornece ao novo jornalismo emergente uma legitimidade para a atividade/negócio em expansão e uma identidade para os seus profissionais" (2005a, p.42). De tal modo, ele identifica o jornalismo, tanto com a idéia de Quarto Poder, quanto com o conceito de "opinião pública", vinculado às teorias democráticas do século XIX e define o papel social de seus agentes:

\footnotetext{
Com a legitimidade da teoria democrática, os jornalistas podiam salientar o seu duplo papel: como porta-vozes da opinião pública, dando expressão às diferentes vozes no interior da sociedade que deveriam ser tidas em conta pelo governos, e como vigilantes do poder político que protege os cidadãos contra os abusos (históricos) dos governantes. (TRAQUINA, 2005a, p.47-48).
}

Três fatos marcam a consolidação da prática jornalística enquanto profissão, segundo Traquina (2005a): o ensino universitário específico, o surgimento de instituições de classe e o estabelecimento de códigos deontológicos. Data de 1860 o primeiro curso universitário voltado ao ensino de jornalismo, na Universidade de Washington, nos Estados Unidos (TRAQUINA, 2005a, p.84). Em 1910 eram quatro cursos semelhantes, mas com um rápido crescimento, passam a 28, em 1920 e 54, em 1927, conforme explica Traquina (2005a, p.85). $\mathrm{Na}$ Europa, o curso demora um pouco mais a se implantar, chegando na França apenas em 1899 e com a Inglaterra, registrando 30\% de jornalistas com formação até os anos 1960 (TRAQUINA, 2005a, p.85-87)

O segundo marco de consolidação mencionado é a criação de associações, clubes e sindicatos profissionais, a partir da segunda metade do século XIX, nos Estados Unidos, Inglaterra e França. As funções dessas instituições, além de "construir uma coesão profissional”, eram fornecer assistência médica, licenças para circulação em ferrovias e mobilizar os profissionais por mudanças nas suas condições de trabalho (FERENCZI apud TRAQUINA, 2005a, p. 82). Mobilizações de classe passam a ocorrer no final do século XIX.

Com as associações de classe surgem também os códigos profissionais. Conforme Traquina, “o primeiro 'código de conduta' localizado para jornalistas apareceu em 1890, e apesar de terem sido registradas 'máximas' rudimentares e claras nos fins do século XIX, ninguém parece ter oferecido um código mais formal até 1911” (2005a, p.88). Em 1900 surge o primeiro código de ética de jornalismo, na Suécia, porém esse somente é adotado em 1920. 
Pouco antes disso, em 1918, o Sindicato Nacional de Jornalistas da França aprova o seu código e, internacionalmente, data de 1939 o estabelecimento de um "código de honra profissional" (TRAQUINA, 2005a, p.88).

Apesar do processo de profissionalização ter se iniciado no século XIX e consolidado no XX, Traquina (2005b) afirma que, além de serem escassos os estudos sobre a profíssão de jornalista anteriores aos anos 1970, mais raros ainda são pesquisas, mesmo mais recentes, na área jornalística em âmbito internacional. Para testar sua hipótese de que "existe uma comunidade jornalística interpretativa transnacional", que o pesquisador prefere denominar "tribo", ele analisa a cobertura jornalística sobre a AIDS em cinco jornais situados em quatro países pertencentes a três continentes diferentes. Várias semelhanças relativas a uma mesma cultura noticiosa entre os veículos de comunicação analisados foram encontradas, tais como critérios de noticiabilidade relativos ao tempo, proeminência do ator e escândalo (TRAQUINA, 2005b). Ao concluir, indica a incompletude do processo:

\footnotetext{
Verificamos que o processo de profissionalização ainda não está completo, e que se desenvolveu nos diversos países em ritmos diferentes, sobretudo condicionado pela existência de liberdades fundamentais. Desenvolveu-se, sobretudo, com os objetivos de melhores vencimentos e condições de trabalho e, ainda, maior prestígio social, numa identificação clara com as chamadas profissões liberais [...] (TRAQUINA, 2005b, p. 189)
}

Outros autores reforçam essa ideia de falta de consolidação da profissão, indicando, inclusive, retrocesso em questões aparentemente já definidas. Érik Neveu (2006) afirma que, cada vez mais se caminha para um "jornalismo de mercado", cuja lógica consiste em uma crescente ambição por parte do mercado jornalístico. Para atingir estes objetivos comerciais, os conteúdos são redirecionados, visando atingir um público maior com ênfase em entretenimento e informação-serviço; e as condições de trabalho dos profisssionais do jornalismo também sofrem fortes modificações (NEVEU, 2006). "Exploração de estagiários (mão-de-obra barata), freelancers e trabalhadores com contratação intermediária, estão entre as formas de exercer esta redução de despesas. A instabilidade na carreira de jornalista é crescente" (NEVEU apud SOARES, 2015, p.16).

O jornalista inserido neste mundo mercantil tem sua preocupação substituída. Enquanto antes era essencial levar à sociedade informações relevantes de qualidade, hoje o importante é levar conteúdos que atraiam o consumidor, e rápido. Devido à concorrência, os 
jornalistas são pressionados a lançar seus materiais o mais rápido possível, perdendo o pouco tempo para reflexão que tinham anteriormente (NEVEU, 2006). Assim, neste novo cenário, o profissional que deseja permanecer na chamada "tribo jornalística" muitas vezes é obrigado a afastar-se de alguns dos princípios que a constituíram originalmente, como sua identidade fundada no papel social que o jornalismo desempenha na democracia moderna.

\title{
3. A profissão no Brasil
}

A história do jornalismo no Brasil tem pouco mais de 200 anos. Ela inicia oficialmente com a chegada da Corte Portuguesa, em 1808. Por mais de um século, a profissão de jornalista no Brasil esteve ligada a um meio termo entre carreira de esfera política e de esfera cultural e seus profissionais a viam como carreira provisória, usada tanto para criar uma renda extra, quanto para fazer contatos (PETRARCA, 2008).

\begin{abstract}
A articulação entre a atividade jornalística e diversas outras tarefas políticas e religiosas marcou a trajetória de muitos personagens que se dedicaram a uma carreira na imprensa durante todo século XIX. Os redatores de jornais acumulavam várias funções, a atividade jornalística tornava-se apenas uma das atividades exercidas, além de um importante instrumento de ação política. A imprensa representava um espaço importante para projeção de partidos e personagens políticos, pois era através do jornal que se fortalecia a carreira na política no período imperial, constituindo-se, assim, como um meio de se chegar à política (RIBEIRO, 2003). Nesse contexto, os jornais encontraram na política a fonte de sua existência e sustento, servindo aos interesses do Império ou àquele dos grupos opositores, manifestando-se nas lutas que ocorreram durante o período de Brasil - Colônia e Império, - tendo inclusive uma influência decisiva nos conflitos políticos pela Independência. (PETRARCA, 2008, p. 3)
\end{abstract}

Apenas no final do século XIX o jornalista especializado passa a ser visto como aquele profissional que vive para coletar e confeccionar notícias. Tal mudança se dá a partir do crescimento do prestígio da reportagem em detrimento da opinião, que até então predominava nos periódicos. O profissional precisa sair para a rua para ver, apurar e relatar o que está acontecendo a todo o momento, literalmente correr atrás da notícia e esse deslocamento tornase sua principal característica (PETRARCA, 2008).

A lógica da imprensa como um lugar de encontro entre figuras de diferentes áreas, em sua maioria membros de uma elite política e cultural, perdurou durante toda a República Velha, de 1889 até 1930. Desta forma, atuar no jornalismo era um meio de oportunidades, devido à visibilidade e à presença de pessoas influentes. Trabalhar na imprensa era algo 
almejado por diversas categorias profissionais da sociedade, e, consequentemente, bastante concorrido, uma vez que representava a mais alta instância de produção cultural e consagração da época (PETRARCA, 2008).

\begin{abstract}
Até a segunda metade do século XX, o jornalismo era considerado um subproduto das belas artes. Alceu Amoroso Lima o definia como "literatura sob pressão". Muitos jornalistas eram também ficcionistas. Devido à ausência de mercado editorial forte, os escritores tinham que trabalhar em outras ocupações para garantir sua sobrevivência. O jornalismo, como a atividade mais próxima - que nesse momento permitia o livre desenvolvimento dos estilos pessoais -, era uma escolha natural para muitos deles. Os periódicos brasileiros seguiam então o modelo francês de jornalismo, cuja técnica de escrita era bastante próxima da literária. Os gêneros mais valorizados eram aqueles mais livres e opinativos, como a crônica, o artigo polêmico e o de fundo. Os jornais, além disso, funcionavam como uma instância fundamental de divulgação da obra literária e de construção de reconhecimento social dos escritores. Era sobretudo através do folhetim que os leitores tomavam contato com os autores e seus trabalhos. Por outro lado, eram também muito estreitas as relações do jornalismo com a política. (RIBEIRO, 2003, p. 147)
\end{abstract}

Foi Getúlio Vargas, em 1938, que regulamentou o primeiro instrumento legal da profissão, além de instituir o primeiro curso superior de jornalismo no país, em 1943, e fixar remuneração mínima e definição de funções, em 1944 (RIBEIRO, 2003). A partir de 1969, tornou-se obrigatório o diploma de nível superior para o exercício do jornalismo, medida que não foi absorvida com rapidez pelo mercado, tanto pela falta de profissionais, quanto por resistência das empresas. Por outro lado, incentivou o aumento de cursos de jornalismo, que eram poucos nos anos 1960 e tiveram um grande aumento quantitativo, chegando, nos anos 1990, a mais de 200 cursos pelo país.

Nos anos 1970 e 1980, o jornalismo brasileiro teve a maior profissionalização dos jornalistas como fruto da regulamentação de 1969, a luta sindical e a assimilação pelos veículos de seu caráter empresarial (NEVEU, 2006). No estado de São Paulo, ocorreram duas greves da categoria, a primeira em dezembro de 1961, e a segunda em maio de 1979. Em 1961, os profissionais reivindicavam $60 \%$ de aumento e piso salarial de dois salários mínimos, 26 mil cruzeiros, na época. O Sindicato dos Jornalistas Profissionais de São Paulo (SJPSP) divulgou que $80 \%$ da categoria recebia um salário mínimo, 13 mil cruzeiros. Após propostas mais baixas e instauração de dissídio coletivo, o Tribunal Regional do Trabalho de São Paulo aprovou 45\% de reajuste nos salários e um piso de 22 mil cruzeiros (ROXO DA SILVA, 2005). 
Já em 1979, o objetivo dos jornalistas de São Paulo era 25\% de aumento salarial e imunidade para os representantes sindicais das redações. Duas assembleias foram realizadas e a proposta de greve foi aprovada por $90 \%$ dos 1.692 jornalistas presentes. Os sindicatos patronais, porém, não modificaram a proposta inicial de $16 \%$ de antecipação, fazendo com que o Tribunal Regional do Trabalho julgasse a greve ilegal (ROXO DA SILVA, 2004). Na sequência, mais de 200 grevistas foram demitidos. Para o pesquisador, a greve foi um aprendizado político, mas revelou despreparo, falta de consciência de classe e de uma tradição de luta. Além disso, esbarrou em questões estruturais: “[...] num país no qual os habitantes são pobres e o jornal é caro, uma greve de jornalistas têm pouco efeito" (ROXO DA SILVA, 2004, p. 6).

Nas décadas de 1980 e 1990, os países sul-americanos passavam por períodos de redemocratização e o jornalismo investigativo teve grande crescimento em países como Argentina, Colômbia e Peru, devido ao avanço da democracia, ao liberalismo econômico e a maior independência dos meios noticiosos em relação ao estado (ROXO DA SILVA, 2007). Esse cenário, em diversos países, fez com que o jornalismo fosse associado a um "quarto poder".

No Brasil, contudo, um estudo de Travancas (1992) realizado com um grupo de 50 jornalistas do Rio de Janeiro, demonstra que seus entrevistados viam a ideia de detentores de poder como uma ilusão. Acreditavam que essa associação ocorria pela falta de definição do próprio jornalista, uma vez que políticos e servidores públicos podiam exercer a função, mas que a nova geração é mais profissional e isenta de poder. Uma das conclusões do estudo é sobre o individualismo dos profissionais.

\footnotetext{
Os jornalistas seriam aparentemente portadores de uma ideologia individualista, apresentando, como já comentei anteriormente, uma postura blasé diante dos fatos e da vida, tentando a todo custo, e usando a profissão como instrumento, ocupar um lugar destacado na sociedade. Isso se explica na busca de notoriedade, várias vezes enfocada por meus informantes. E ajuda também a compreender o porquê da acirrada competição entre os colegas. (TRAVANCAS, 1992, p. 104)
}

Tal observação contrasta com a ideia de uma comunidade interpretativa que partilha de uma "cultura noticiosa" (TRAQUINA, 2005b), porém reforça a observação de que o processo 
de profissionalização ainda não pode ser considerado consolidado. O que nos possibilita afirmar que, mesmo partilhando de valores comuns, os jornalistas têm dificuldades em se perceber enquanto categoria profissional, sobretudo pela dificuldade em se assumir enquanto trabalhadores assalariados e não como profissionais liberais e pela competição alimentada pela concorrência entre os meios. Comentando os resultados do estudo, Travancas (1992) considera que essa visão da categoria como desprovida de poder impede que os profissionais lutem pelos seus próprios interesses. É o que pode ser percebido em dois episódios mais recentes. Em 2004, a Federação Nacional dos Jornalistas (FENAJ) sugeriu a criação do Conselho Federal de Jornalismo com o objetivo de controlar o exercício profissional, nada que se diferenciasse dos conselhos de profissões como médicos, advogados e engenheiros. $\mathrm{O}$ projeto de lei foi retirado quando os veículos unanimemente criticaram a proposta como forma de reprimir a liberdade de expressão (NEVEU, 2006). Para Albuquerque,

O problema da falta de um acordo mínimo dos jornalistas brasileiros em torno das questões fundamentais de sua profissão voltou a se fazer evidente mais recentemente, diante do anúncio da criação de um Conselho Federal de Jornalismo (CFJ) pelo governo Lula. A proposta foi saudada pela Federação Nacional dos Jornalistas (FENAJ) como uma conquista histórica dos jornalistas e da sociedade, e condenada pela maioria das empresas jornalísticas como um atentado contra a liberdade de expressão no país (2004, p. 8)

Em 17 de junho de 2009, o Supremo Tribunal Federal derrubou a exigência do diploma em jornalismo para o exercício da profissão, imposta pelo decreto-lei 972/69. Segundo matéria publicada no portal de notícias da Globo (ABREU, 2009), o presidente do STF, Gilmar Mendes, afirma que não necessariamente o profissional graduado tenha mais qualidades no exercício do jornalismo e comparou jornalistas com chefes de cozinha.

Em agosto de 2014, o Conselho de Comunicação Social do Congresso Nacional aprovou parecer favorável à exigência do diploma para jornalistas, porém, o órgão não tem poder de aprovação legislativa e somente auxilia os parlamentares em matérias relacionadas à comunicação (MENDES, 2014). Beth Costa, Secretária Executiva da Federação Internacional dos Jornalistas e membro da Comissão de Ética da FENAJ, que foi presidente da instituição de 1998 a 2004, defende a formação como garantia de qualidade mínima do jornalista, pois a escola ensina técnicas, teorias, e princípios éticos fundamentais para o exercício da profissão (COSTA, s/d). 
Para Albuquerque (2004), falta acordo acerca do conjunto de princípios que definam quem é o jornalista e como ele deve pautar seu comportamento, e um exemplo disso é a polêmica sobre o status de jornalista ou não do assessor de imprensa.

O problema da falta de um acordo mínimo dos jornalistas brasileiros em torno das questões fundamentais de sua profissão voltou a se fazer evidente mais recentemente, diante do anúncio da criação de um Conselho Federal de Jornalismo (CFJ) pelo governo Lula. A proposta foi saudada pela Federação Nacional dos Jornalistas (FENAJ) como uma conquista histórica dos jornalistas e da sociedade, e condenada pela maioria das empresas jornalísticas como um atentado contra a liberdade de expressão no país (os defensores do projeto responderam a esta acusação sustentando que a oposição ao projeto escondia uma defesa da liberdade de empresa, antes que da liberdade de imprensa). Muitos jornalistas não evidentemente vinculados à FENAJ ou aos interesses das empresas se posicionaram contra ou a favor do projeto, alegando variadas razões. Alguns o fizeram de maneira mais impetuosa, atacando tanto os argumentos quanto os adversários, enquanto outros escolheram lidar com o problema de maneira mais ponderada. (ALBUQUERQUE, 2004, p. 8)

A realidade contemporânea dos profissionais de jornalismo brasileiros, que inclui individualismo e falta de consciência de classe, pode ser confirmada pelos resultados das duas pesquisas já mencionadas (PERFIL, 2012; FÍGARO, NONATO, GROHMANN, 2013). Com a expansão do capitalismo financeiro e suas transformações em todo o mundo, o jornalismo ganha maior importância para os negócios e acaba se submetendo às demandas do setor comercial da empresa, o que resulta na precarização dos vínculos empregatícios.

\begin{abstract}
A reestruturação produtiva ocorrida no mundo do trabalho, principalmente a partir dos anos 1990, transformou as relações de trabalho. Foi a partir dessa década que aumentou o número de jornalistas contratados sem registro em carteira profissional, abrindo caminho para o surgimento de novas formas de contratação, como a terceirização, contratos de trabalho por tempo determinado, contrato de pessoa jurídica (PJ), cooperados e freelancers, entre outros. São os jovens, não sindicalizados, que mantêm vínculos precários, trabalham entre oito e dez horas por dia e em ritmo acelerado. $O$ fato de a maioria dos freelancers receberem $o$ pagamento a partir de nota fiscal fornecida por um terceiro e trabalharem no setor de revista e Internet dá indicações claras de onde estão os problemas contratuais. (FIGARO, NONATO, GROHMANN, 2013, p. 44)
\end{abstract}

A seguir, apresentaremos os resultados da pesquisa realizada com egressos do Curso de Jornalismo da Universidade Federal de Uberlândia que indicam de modo ainda mais veemente essa fragilização da noção de categoria profissional entre os jornalistas neófitos. 


\section{Desenho e resultados da pesquisa}

A pesquisa aqui descrita tem como seu objeto de estudo o curso de Comunicação Social/Habilitação em Jornalismo da Universidade Federal de Uberlândia. Criado em 29 de agosto de 2008 (BRASIL, 2008), o curso recebeu sua primeira turma em 2009 e foi reconhecido no dia 15 de outubro de 2013, através da Portaria n ${ }^{\circ}$ 515/MEC/SERES. Ainda em 2013, alcançou a primeira colocação nacional na classificação do Inep/MEC para cursos de Jornalismo de todo o país. A nota do Jornalismo UFU foi 4,47 pontos, que confere conceito cinco, recebido apenas por oito cursos de Jornalismo entre todos os avaliados. ${ }^{5}$

O estudo "Egressos de Jornalismo/Ufu no Mercado de Trabalho..." foi desenvolvido entre maio de 2014 e fevereiro de 2015. Para tanto foram realizadas pesquisas bibliográficas e documentais, além de questionário anônimo aplicado aos 49 egressos diplomados pelo Curso de Jornalismo da UFU. O instrumento era composto por 30 perguntas, algumas com opção de comentário, além de apresentação das 39 disciplinas para avaliação do egresso sobre a contribuição de cada uma em suas atuais atividades jornalísticas, totalizando 69 tópicos para resposta dos sujeitos da pesquisa.

Ainda como parte dos procedimentos metodológicos foram feitas dez entrevistas com egressos de diferentes áreas de atuação. Esta amostra foi escolhida por conglomerados (GIL, 2002) por representar cerca de $20 \%$ do total de 49 jornalistas formados pela UFU, quantidade ainda mais representativa quando considerado que apenas 28 egressos afirmaram estar exercendo a profissão, o que faz dos entrevistados mais de um terço dos inseridos no mercado de trabalho. Os entrevistados foram escolhidos visando a maior diversidade de áreas de atuação quanto possível. Dentre aqueles que atuam na mesma área, tiveram preferência os que estavam inseridos em empresas mais consolidadas.

Os resultados obtidos com o estudo acima descrito permitem lançar olhares variados sobre diversas perspectivas em torno da formação do jornalista e sua inserção no mercado de trabalho. No presente artigo, optamos por recortar aqueles dados que apontam para a percepção do profissional neófito enquanto categoria. Para tanto, detalharemos abaixo os espaços de atuação dos egressos respondentes da pesquisa, bem como suas posições sobre

$\overline{{ }^{5} \mathrm{O}}$ resultado completo da classificação feita pelo Inep/MEC está disponível em: $<$ http://pesquisa.in.gov.br/imprensa/jsp/visualiza/index.jspdata $=06 / 12 / 2013$ \&jornal $=1$ \&pagina $=65 \&$ totalArquivo $\underline{\mathrm{s}=264}>$. Acesso em: 17 maio 2015. 
alguns temas como: condições de trabalho, satisfação e dificuldades, registro profissional, obrigatoriedade do diploma, sindicalização e necessidade de autorregulamentação.

Ao observar o perfil geral dos egressos respondentes encontramos: $72 \%$ com idades entre 23 e 30 anos, $26 \%$ entre 18 e 22 e apenas um com mais de 31 anos. $80 \%$ são mulheres, a grande maioria são brancos $(85 \%)$, solteiros $(91 \%)$, e $20 \%$ cursou ou cursa pós-graduação. Como já mencionado, entre os 46 egressos do curso de jornalismo da UFU respondentes do questionário, apenas $61 \%$ exercem a profissão e os números a seguir tomam como total apenas as respostas desses 28 sujeitos que trabalham na área de comunicação social. Quanto aos espaços de atuação, encontramos em primeiro lugar os veículos de comunicação (37\%), seguidos por assessoria de imprensa $(23 \%)$ e outros $(23 \%)$, que não freelancer $(3 \%)$, academia (7\%) e empreendedorismo (7\%). Entre os jornalistas que trabalham em veículos de comunicação, a maior parte atua na área de telejornalismo $(33,33 \%)$ e webjornalismo $(27,78 \%)$, seguido pelo jornalismo impresso (22,22\%). Uma quantidade expressiva dos jornalistas empregados tem um único emprego (93\%), contra 7\% que possuem mais de uma ocupação.

Questionados sobre a quantidade de jornalistas contratados nos locais de trabalho chegou-se, a partir da média simples das respostas obtidas, ao número de sete profissionais. Deve-se destacar, porém, casos de respostas extremas, como "Somente Eu", com cinco repetições, e "Aproximadamente 40", com apenas uma menção. A renda média da maior parte deles é de um a dois salários mínimos (57\%), seguido por renda entre dois e três salários (21\%). Nenhum egresso possui a renda média com atividades jornalísticas acima de cinco salários mínimos. A maioria trabalha de cinco a oito horas por dia (64\%) e está satisfeita com seu trabalho (64\%). Três pessoas comentaram a questão destacando a insatisfação com sua remuneração. Quanto ao registro profissional como jornalista no Ministério do Trabalho, 47\% dos jornalistas que exercem o ofício possuem, enquanto a maioria, não (53\%).

Quanto à obrigatoriedade do diploma para o exercício do jornalismo, uma pequena maioria de 63\% é a favor. As outras respostas, que somam 37\%, se dividem entre egressos que acreditam na obrigatoriedade de alguma formação superior para o desempenho da atividade jornalística (28\%) e aqueles que não defendem nenhuma das opções apresentadas (9\%). Algumas pessoas optaram por comentar sua resposta: 
[...] o argumento de que o jornalista formado está mais bem preparado na teoria e na prática para o mercado de trabalho aparece mais de uma vez. Em um comentário específico, o egresso, apesar de defender que alguns dos melhores jornalistas brasileiros não têm curso superior na área, afirma que em algumas funções específicas, como editor, o diploma é necessário. (SOARES, 2015, p. 42)

Apenas 7\% dos respondentes é filiado a sindicatos, dentre eles, o Sindicato dos Trabalhadores de Tecnologias da Informação e o Sindicato dos Trabalhadores Técnico Administrativos em Instituições Federais de Ensino Superior (Sintet/UFU). O número de egressos que participam ou participaram de movimentos sociais, associações ou organizações é ainda menor, apenas 4\%. Questionados sobre a necessidade de criação de um órgão de autorregulamentação da profissão de jornalista, a grande maioria (83\%) é a favor, enquanto $17 \%$ são indiferentes e nenhum se manifestou contrário. Nesta questão, o “[...] único comentário obtido ressalta a importância de que o órgão apenas sonde os materiais antiéticos produzidos, sem censurar a liberdade de expressão dos veículos” (SOARES, 2015, p.42-43).

Aos resultados apresentados acima, acrescentou-se as entrevistas com 10 jornalistas de variadas áreas de atuação (Jornal Impresso, Rádio, Assessoria de Imprensa, TV pública, TV privada e mestrado, Marketing Digital, Design Gráfico, Marketing de Conteúdo, Representação Internacional e Empreendedorismo), o que possibilitou identificar algumas tendências, também observáveis na percepção do profissional enquanto categoria. Uma primeira constatação foram algumas características comuns aos egressos que trabalham em meios tradicionais e outras entre os egressos que seguem meios não tradicionais, permitindo dividi-los em dois grupos. As considerações que seguem adotam essa divisão como critério.

\section{Algumas considerações}

Ao analisar as condições de trabalho, sobretudo no que diz respeito à rotina de atividades e ao salário, foi possível perceber uma discrepância entre os dois grupos de jornalistas entrevistados. Dentre os cinco egressos que atuam em meios tradicionais, quatro se dizem satisfeitos nesse quesito. Já entre aqueles que praticam atividades não tradicionais, três se mostram insatisfeitos com seus salários e rotinas, um está parcialmente satisfeito e um está satisfeito. Por esses resultados, é possível afirmar que entre os jornalistas que compõem essa 
amostra, aqueles empregados em meios tradicionais estão mais satisfeitos com suas condições trabalhistas do que os que estão em meios não tradicionais.

Os profissionais também falaram sobre as dificuldades encontradas no dia-a-dia da carreira. Entre o grupo de egressos atuante nos meios tradicionais, destaca-se a falta de tempo para o desenvolvimento das atividades jornalísticas e a complexidade nas relações com pessoas e empresas, como fontes e clientes. Já entre os egressos que se encontram fora do jornalismo tradicional, as principais dificuldades observadas estão relacionadas à falta de conhecimento na nova área da comunicação em que atua e as relações complexas com pessoas e empresas, também.

Os relatos corroboram os resultados percebidos no questionário quanto à baixa percepção do jornalista neófito enquanto categoria profissional e permitem avançar, distinguindo entre os dois grupos. Os egressos que trabalham em meios tradicionais aparentam ter maior percepção do jornalista enquanto classe profissional. De qualquer modo, pode-se afirmar que a maior parte dos respondentes não apresenta grande interesse pelo tema, pois como o questionário também apontou, 93\% deles não são filiados a sindicatos e nunca participaram de movimentos sociais, associações ou organizações (96\%).

\begin{abstract}
Acredita-se que o fato de que os egressos que trabalham em meios não tradicionais perceberem menos a categoria jornalística esteja diretamente ligado às novas formas de trabalho. As entrevistas mostraram que estes jornalistas trabalham com um número reduzido de colegas e, muitas vezes, em suas próprias casas. Este distanciamento entre os jornalistas diminui as oportunidades para o debate sobre condições de trabalho e o compartilhamento de ideias, algo que já havia sido apontado também nas pesquisas sobre perfil nacional dos jornalistas. Pode-se perceber ainda, que os egressos do Jornalismo/UFU, em geral, não mostram grande interesse por assuntos relativos à sindicato, organizações de classe e outras temáticas relacionadas ao profissional enquanto categoria [...] (SOARES, 2015, p.52).
\end{abstract}

Diante dos resultados expostos, é possível afirmar que o egresso de Jornalismo/UFU é a favor da obrigatoriedade do diploma para o exercício da profisssão de jornalista e da criação de um órgão de autorregulamentação da profissão de jornalista, embora não demonstre grande interesse pela sua categoria. O jornalista formado pela UFU não é filiado a sindicatos, nunca participou de movimentos sociais, associações ou organizações e não possui registro como jornalista no Ministério do Trabalho.

Essa tendência de desmobilização já havia sido apontada em estudos anteriores, conforme mencionado alhures (TRAVANCAS, 1992) e nas pesquisas de Fígaro, Nonato e 
Grohmann (2013) e Perfil do Jornalista Brasileiro (2012), e nos coloca um duplo desafio. Em primeiro lugar, aponta para a necessidade de oferecer aos novos profissionais uma formação que ultrapasse o mero tecnicismo e permita a eles perceber o papel social do jornalista, oferecendo referências para nortear suas ações. Por fim, indica a urgência de repensarmos os modos de representação profissional, ainda fincados sobre um modelo tradicional de organização trabalhista, não mais coerente com a fluidez dos processos produtivos contemporâneos.

\section{Referências}

ABREU, Diego. STF derruba exigência de diploma para exercício da profissão de jornalista. g1: o portal de notícias da Globo, 17 jun. 2009. Disponível em: http://migre.me/qZVZ1 Acesso em: 5 dez. 2014.

ALBUQUERQUE, Afonso de. A identidade jornalística no Brasil: Algumas questões teóricas e metodológicas. Revista e-compós, Niterói, Rio de Janeiro, Universidade Federal Fluminense. v. 1, p.1-14, dez. 2004. Quadrimestral. Disponível em: http://migre.me/qZW2A Acesso em 09 outubro 2014.

BRASIL. Universidade Federal de Uberlândia. Faculdade de Educação. Projeto de Criação do Curso de Comunicação Social : Habilitação em Jornalismo. Uberlândia, 2008. Disponível em: http://migre.me/qZW53 Acesso em: 20 dez. 2014.

COSTA, Beth. Diploma em jornalismo: uma exigência que interessa à sociedade. s/d. Disponível em: http://migre.me/qZW6L Acesso em 20 dez. 2014.

FIGARO, Roseli (Org.); NONATO, Claudia; GROHMANN, Rafael As mudanças no mundo do trabalho do jornalista. São Paulo: Salta, 2013.

GENRO FILHO, Adelmo. O segredo da pirâmide - Para uma teoria marxista do jornalismo. Porto Alegre : Tché, 1987. 
GIL, Antonio Carlos. Como elaborar projetos de pesquisa. 4. ed. São Paulo: Atlas, 2002.

GOMIS, Lorenzo. Teoria del periodismo: como se forma el presente. Barcelona: Paidós, 1991.

KUNCZIK, Michael. Conceitos de Jornalismo: norte e sul - manual de comunicação. São Paulo: Edusp, 2002.

MENDES, Priscilla. Conselho do congresso defende diploma obrigatório para jornalista. G1: O portal de notícias da globo. Online, 06 agosto 2014. Disponível em: http://migre.me/qZW7X Acesso em 5 dez. 2014.

NEVEU, Érik. Sociologia do jornalismo. São Paulo: Edições Loyola, 2006.

PERFIL do jornalista brasileiro. Características demográficas, políticas e do trabalho. 2012. Programa de Pós-graduação em Sociologia Política da Ufsc em convênio com a Federação Nacional dos Jornalistas - FENAJ. Apoio: Fórum Nacional de Professores de Jornalismo FNPJ e Associação Brasileira de Pesquisadores em Jornalismo - SBPJor 77 p. Disponível em: http://migre.me/qZW8L Acesso em: 20 jun. 2014.

PETRARCA, Fernanda Rios. Por uma Sociologia Histórica do Jornalismo no Brasil. In: Congresso Nacional de História da Mídia, 6., 2008, Niterói. Anais eletrônicos... Niterói: Rede Alfredo de Carvalho, 2008. Disponível em: http://migre.me/qZWdX Acesso em: 30 maio 2014.

RIBEIRO, Ana Paula Goulart. Jornalismo, literatura e política: a modernização da imprensa carioca nos anos 1950. Revista Estudos Históricos, v. 1, n. 31, p. 147-160, 2003. Disponível em: http://migre.me/qZWfs Acesso em: $10 \mathrm{dez} .2014$. 
ROXO DA SILVA, M. A. Os jornalistas e sua greve: Consciência de classe e debate político. In: II Encontro Nacional da Rede Alfredo de Carvalho, Florianópolis, 2004. Disponível em: http://migre.me/qZWin Acesso em: 12 out. 2014.

. Sindicato, memória e história - a greve dos jornalistas de 1961. 2005. In: I Encontro Nacional da Rede Alfredo de Carvalho, Novo Hamburgo/RS, 2005. Disponível em: http://migre.me/qZWow Acesso em 12 out. 2014.

_. Jornalistas, pra quê? Militância sindical e o drama da identidade profissional. Universidade Federal Fluminense. 2007. 258f. Tese (Doutorado em Comunicação). Niterói, 2007. Disponível em http://migre.me/qZWkJ Acesso em 20 out. 2014.

SOARES, Michelle Júnia. Egressos do Jornalismo/UFU no mercado de trabalho: mapeamento sobre o perfil e inserção profissional dos jornalistas formados pela Universidade Federal de Uberlândia. 2015, 132 f. Trabalho de Conclusão de Curso (Graduação em Comunicação Social/Habilitação em Jornalismo) - Faculdade de Educação, Universidade Federal de Uberlândia, Uberlândia, 2015.

SOUSA, Jorge Pedro. A notícia e seus efeitos. Coimbra : Minerva, 2000.

TRAQUINA, Nelson. Jornalismo: questões, teorias e estórias. Lisboa : Vega, 1993.

_. Teorias do Jornalismo - porque as notícias são como são. 2.ed. Florianópolis: Insular, 2005a. (Volume I).

- Teorias do Jornalismo: a tribo jornalística - uma comunidade interpretativa transnacional. 2.ed. Florianópolis: Insular. 2005b. (Volume II).

TRAVANCAS, Isabel Siqueira. O mundo dos jornalistas. 3. ed. São Paulo: Summus Editorial, 1992. 
WOLF, Mauro. Teorias da Comunicação. São Paulo : Presença, 1995.

ZELIZER, Barbie. Takingjournalism seriously. London : Routledge, 2004. 